\title{
EAl Endorsed Transactions

\section{Art and artificial intelligence, a window into the future of the evolution of contemporary society}

\author{
Alejandra Elena Marinaro ${ }^{1, *}$ \\ ${ }^{1}$ Universidad Abierta Interamericana. Latin American Bio Art Laboratory - Executive Director
}

\section{Abstract}

INTRODUCTION: The present work deals with the incorporation of artificial intelligence in the process of artistic creation.

OBJECTIVES: The objective of this article is to analyze the work developed at the Latin American Bio Art Laboratory in order to incorporate artificial intelligence into artistic works and its influence on the current social context.

METHODS: This study is fundamentally based on the analysis of artificial intelligence applied to art, the consequences of its use on copyright, and the development achieved in these areas by the Latin American Bio Art Laboratory.

RESULTS: Contribution of the Latin American Bio Art Laboratory to the development of the conceptually complex work Robotika by artist Joaquín Fargas, that connects a deep human feeling with the incorporation of artificial intelligence in its evolution

CONCLUSION: Art is always at the forefront of social change, offering the possibility of bringing the future closer to the present with a different outlook.

Keywords: Bioart, Artificial Intelligence, Latin American Bio Art Laboratory.

Received on 14 January 2020, accepted on 21 January 2020, published on 22 January 2020

Copyright (C) 2020 Alejandra Elena Marinaro et al., licensed to EAI. This is an open access article distributed under the terms of the Creative Commons Attribution license (http://creativecommons.org/licenses/by/3.0/), which permits unlimited use, distribution and reproduction in any medium so long as the original work is properly cited.

doi: 10.4108/eai.13-7-2018.163834

*Corresponding author. Email:marinaro.alejandra.e@gmail.com

\section{Introduction}

Over time, art and artists have imagined and captured in their works concepts and ideas that only became reality many years later. It is the case for example of Leonardo Da Vinci, he conceived flying machines and shaped them artistically, it was unthinkable for his contemporaries that these devices could become a reality, nevertheless the passage of time and the technological advances gave him the reason and centuries later the helicopter appeared. In this aspect it seems unavoidable to refer to Paul Klee when hesaid, "Art does not reproduce the visible, it makes it visible".[1]

Art also makes visible conflicts, political tensions and realities that society does not want to see or prefers to ignore and recreates scenarios so that human beings can stop and rethink fundamental questions for their survival.
A clear and current example in this sense is the case of the Handles[2] Installation by artist Haegue Yang; the work includes industrial design handles, Shiny vinyl figures on the walls, the sound of birds and experimental music, together with large wheeled sculptures covered with bells that, when activated, propose a dance that adds new sounds to the scene evoking shamanic rituals. Throughout the day also, recordings of birds singing during a summit between North and South Korea in 2018 can be heard by the visitors. The singing of the birds was captured by journalists who tried to record a private conversation between the political leaders, but could only capture environmental sounds, a metaphor that contrasts political conflicts with the harmony of nature.

Artists have already taken art to outer space by conceiving poetry specially designed for zero-gravity, such is the case of Eduardo Kac who, as part of his Space Poetry project, displayed his work Inner Telescope in 2017 with French astronaut Thomas Pesquet on the 
International Space Station. In the artist's words "It is possible to write and draw conventionally on board a space station, but this does not represent a significant stimulus for the creation of a poetic language proper to this environment. The new material reality of ordinary access to weightlessness and space creates the cultural context for the emergence of genuine space poetry"[3]. The poem alludes to the word I (moi in French) and consists of a three-dimensional object that is assembled from two sheets of paper, one cut in the shape of the letter $M$ that suggests the human figure with a central hole, letter $\mathrm{O}$, which refers to a cut umbilical cord, into which another sheet in the shape of a cylinder, letter I, is inserted, which crosses both letters. This poetry has neither up, nor down, nor forward, nor backward showing the liberation of humanity from gravitational limits.

In October 2018, Christie's auctioned for the first time the work conceived by the artistic collective Obvious "Portrait of Edmond de Belamy" generated by an artificial intelligence algorithm. Basis of the artwork are 15,000 real portraits, which were created between the 14th and 20th century. Building on this data set, an algorithm was developed to teach to the software the rules of portrait painting.

Another algorithm was used to create a series of new images by mixing the portraits in various ways, from which the AI itself selected the final image. On it, as the artist's signature, the algorithm identification can be read in italics.[4]

In 2019 the artist Mario Klingemann, presented his work "Memories of Passers-by I" created with artificial intelligence that presents, on two framed screens, imaginary portraits of men and women generated in real time. This is the first work that does not show an curedby-humans end product, it is an autonomous artificial intelligence work, that runs in real time; constituting an infinite, and in a certain form ephemeral, work since the portraits that are visualized never repeat themselves.

The above mentioned works are clear examples of the avant-garde and prophetic role of art with respect to situations that the human beings will not be able to avoid during its evolution, that is why today artificial intelligence is seen as an element that is inevitably incorporated into the conception and generation of art. This incorporation does nothing more than to show and expose the future to which society will surely have access and the ethical dilemmas and conflicts it will undoubtedly have to face as a result of its inclusion.

For several years now, the Latin American Bio Art Laboratory has been working on these aspects and has developed various works that have always sought to highlight this anticipatory and questioning view of art in the face of problems such as climate change, the extinction of species and the future of the human race, among others. Several of them focused on the theme of bio-art and others on the application of multimedia technologies, in this article I will especially address the work of the artist Joaquin Fargas, Robotika.

\section{The Latin American Bio Art Laboratory}

The Latin American Bio Art Laboratory (LabLat) was born out of the idea of bringing together artists, scientists and technologists who were willing to rethink concepts and trends imposed on the current social context and who, through art, would seek new horizons and stimulate future generations to innovate in scenarios that seem to be unchangeable.

It is from innovation and science that the great social revolutions have emerged, and in this way the Latin American Bio Art Laboratory became a creative powerhouse from which a countless number of artistic works have emerged and have been exhibited both locally and internationally.

In addition to this space for debate and a platform for the development of works, the laboratory offers residencies for artists from other countries who are interested in immersing themselves in the Latin American art scene.

It is precisely within the laboratory that the artist Joaquín Fargas developed, among other works, Robotika which incorporates in its conception the use of artificial intelligence as the key driver of its existence.

For several years LabLat has been experimenting with various algorithms in order to train devices for the generation of artwork. We worked with supervised and unsupervised automatic learning, in the latter case we sought to group the variables by creating maps of trends or behavioral patterns depending on the type of data. Experiments with image and sound recognition were carried out and several projects involving these technologies were completed.

Without a doubt, the work that stimulated and awoke in this laboratory the interest for researching into issues related to artificial intelligence and neural networks was the Big Brain Project, by the artist. This artistic work consisted of the assembly of two interconnected neuronal networks that combined biological processes with technological devices for the reception of stimuli and the transmission of information. This installation connected a neural network established in the city of Linz, Austria with another one hosted in the city of Buenos Aires, Argentina. Both networks had biological components that were stimulated from the actions of the visitors generating reactions in these components that were translated into brain waves. These waves generated by each of the networks merged giving birth to the brain waves of a great universal brain.

The realization of this work generated, in the creative and multidisciplinary team of the laboratory, questions about the duality between the natural and the artificial, between individuality and sociability, but above all it generated the motivation to investigate in artificial intelligence, focusing in machines that imitate the thinking dynamics of the human brain. 


\section{Artificial intelligence and art}

In order to define what artificial intelligence is, several authors have tried to establish the objective that this technology pursues. Depending on how these objectives are defined, Russell and Norvig classify the different definitions into four categories [5]:

- Systems that act like humans: systems and programs with the ability to process natural language, represent knowledge, reason automatically and learn to adapt to new circumstances (Kurzweil, 1990).

- Systems that think like humans: systems capable of automating mental operations, such as decision-making or learning (Bellman, 1978).

- Systems that think rationally: systems that try to emulate rational logical thinking and to reach conclusions according to a series of universal laws of thought defined by logic (Winston, 1992).

- Systems that act rationally: systems that seek to extend rationality beyond the laws of logic to include other elements, such as uncertainty, autonomy, change, etc. (Poole, Mackworth and Goebel, 1998).

Several artificial intelligence techniques have shown that it is feasible to model creative activities in many fields: arts, sciences and technologies, among others. Some of these techniques are:

- Expert systems: systems in which the reasoning of a human expert is emulated through a set of rules in a restricted and limited field of knowledge. [6] (Moriello, 2001)

- Reasoning based on the case method: systems based on a great variety of cases and the solution of these cases constituting learning by analogy. [7] (Moriello, 2005)

- Artificial Neural Networks: software based on multiple parallel, interconnected processors that is trained through the recognition of a variety of provided patterns. Based on the training the algorithms can work with inaccurate or incomplete and even contradictory data [6] (Moriello, 2001)

- Genetic algorithms: Each possible solution to a problem is coded by a chain (chromosome) of characters (genes) of fixed length. At random, an initial population is generated, which is evaluated using established performance criteria and, in each cycle, chooses the best solutions, to combine them and generate new solutions [8] (Garzón \& Torres, 2011).

- Multi-agent systems: Set of intelligent agents that cooperate with each other to develop a task. Its efficiency improves by increasing the knowledge base with facts and broader rules [9] (Garzón \& Torres, 2012)

As can be noted, there are several computational tools developed with the objective of capturing intelligence in machines; this, together with the increasing potential in data processing, could allow computers to have more and more creative features.

Artificial Intelligence (AI) is nowadays a field of multidisciplinary study in which its capacity of automatic learning is particularly outstanding. Thus, we seek to define a problem through an algorithm and then choose the best strategy to formulate a new hypothesis from it or find a solution. Neural networks optimize these responses by following the model of the human brain even without achieving its extreme level of complexity.

New questions arise from the use of artificial intelligence. Is it possible for machines to act intelligently in the same way as people? [10] (Searle, 2000) Can machines, through an artificial intelligence scenario, think or act with their own intelligence? [11] (Kaku, 2014) Can a machine create a work of art? Is there a co-creation scenario between the artist and the robot or the algorithm? One of the most interesting aspects to analyze in the training of the algorithms is the latent space that is created, where the artificial intelligence accumulates the new variables and conclusions; that multidimensional space, in which the mathematical formulas relate characteristics of the images or sounds, is what allow it to make a network or sequence that orders them in a specific way. A visualization of this concept can be found in the Google Freefall experiment, that offers a threedimensional space (spherical, wave, timeline or big bang) in which we can navigate among the most famous works of art in several museums around the world.[12].

In this same sense, the artist Mario Klingemann programmed for Google the algorithm for the project called $\mathrm{X}$ degrees of separation. This development connects two works of art showing, according to the conclusions of the software, which could be the diverse related artistic works that exist between them. For this purpose, the algorithm analyzes color, pixels and other variables and can link any work with another through time and space.

An important milestone in the evolution of artificial intelligence applied to art is the appearance in 2014 of the GANs or Generative Adversary Networks concept. This Ian Goodfellow's idea, allowed a breakthrough in the development of autonomous learning. Generative Adversary Networks are based on the confrontation of two competing neural networks in a continuous game that adds up to zero, so the loss or gain of each of those networks is offset by the loss or gain of the other. In this way, the generative network produces samples of what it is intended to create, for example, images or sounds. It is at this point that the second network analyzes the material generated by the generative one and establishes whether it matches what is being sought. It is precisely from this idea that the learning systems began to auto train with greater speed and precision, currently reaching the extreme of generating photos and videos of non-existent people with a high degree of accuracy; images that cannot be differentiated from real stuff.

The most used artificial intelligence generating software is

Deep Dream: what is shared online

Processing[13]: which is an open source programming language

DCGAN[14]: Can be used under license of Robbie Barrat 
Clip Studio: Can be used under license, is a special software for generating Manga and color illustrations and drawings.

\section{The problem of copyright when in the creation arises from an algorithm}

When analyzing the ownership of a work of art, three aspects should be considered:

Physical ownership of the work of art: It consists of the right to have possession of the work and therefore to dispose of it.

Copyright: It is the economic right of the author to exploit the commercial value of the work, it allows the artist to prevent his work from being copied and this is what gives it economic value

Moral Rights: It is a protection that seeks to avoid an inadequate treatment of the work

These three concepts can be owned by different subjects or individuals.

Copyright is the tool by virtue of which protection is granted to works of art that are expressed through the literary or artistic genres; it aims at the creations of the spirit expressed in such a way that they can be perceived, and it is from this right that artists can prevent their works from being copied, recognizing the intrinsic economic value of each one of them.

It is interesting to consider these same aspects in order to analyze copyright in relation to a work developed by an artificial intelligence, since current copyright legislation only recognizes authorship to human beings.

The study of the development of computer programs that behave creatively is known as "computer creativity"[15]. In these cases the software is not a tool that the artist uses to improve his creation, it is a system that by itself creates works without human intervention, except at the moment of elaboration of the algorithm, and that shows an originality equivalent to human beings. This type of art is characterized by the randomness of its composition, evolution, change in a chaotic environment and is created exclusively by software.

The conception of copyright is related to the principle of authorship according to which the ownership of the work belongs to the author (natural person), being a fundamental requirement the originality of the work. Therefore, the owner of the right is the person who created the work. If the work is the result of the collaboration of several authors, then the ownership of the right shall belong to all of them.

The controversy arises since in general the algorithms that are used to generate the works with artificial intelligence were not developed by the artists who conceived such works. The question would be whether the author of the work is the artist or the artist and the programmer who developed the algorithm or the algorithm itself is the author of the work.

Many countries have not yet made progress in their legislation to address these issues, the most advanced countries, as we mentioned earlier, only recognize copyright for human beings. There is some basic guidance in the "Compendium of US Copyright Office Practices", which says that works of art software-produced with no creative input or intervention from a human can't be given authorship. But it looks like the US Patent and Trademark Office feels this definition won't hold up when artificial intelligence was involved in creative works as the "collaboration" between humans and machines continues to get more intricated.

As algorithms become increasingly advanced, and a commonplace in the creative workflow of digital artists, its capability of making new and creative material is requiring changes to copyright law; the problem has ceased being theoretical and will have to be answered.

As for the copyright on the artworks created with artificial intelligence, special attention must be paid to the right of use of the software with which it is developed. The artist must have a specific license for the use of the software so that the copyrights for the realization of the work are recognized and do not generate controversy.

Another aspect to be considered is the copyright of the data used to feed the artificial intelligence, until now artists have generally resorted to classical works of art since those rights have already expired. But what happens if an artificial intelligence is feeded with copyrighted material? Is it possible to say that artificial intelligence creates a copyright-infringing work?

The World Intellectual Property Organization organized last year in Geneva the "WIPO Conversation on Intellectual Property (IP) and Artificial Intelligence (AI)"; one of the conclusions of the meeting was that copyright and trademarks may not be enough to protect an AI-related invention, so companies are tempted to jealously guard training data used for machine learning. The reversion to secrecy runs against one of the principles of the intellectual property system, where public disclosure is a condition for limited protection.

The world might need other forms of protection that do not currently exist; it will undoubtedly be necessary in the near future for countries' legislative systems to make progress in copyright protection of purely algorithmic works of art in which human intervention does not exist or is limited to a "push button thing". It is in that direction where artificial intelligence leads and the lack of recognition of such rights would harm the development of the activity.

\section{Robotika}

As mentioned above, this artwork was developed at the Latin American Bio Art Laboratory.

This work by Joaquín Fargas was imagined and conceived by the artist more than ten years ago, at that time there was no technology to develop it and it remained in a latent state.

The conceptual idea of this artwork Robotika, The Nannybot, refers to a female image whose functions are to 
preserve humans, take care of the baby and protect the environment around the child. It is a robot equipped with artificial intelligence whose mission is to collaborate with the survival of humanity in the future, when facing the threat of extinction. Each Robotika would carry cryopreserved human embryos in order to transport life and humans to other places in the universe. These robots would function as galactic arcs which would transport the seed of life away from this planet in search of appropriate places for its development and would in turn carry with them the intelligence developed to care for the future babies and their habitat by providing them with the proper conditions for their emotional development.

A constant in Joaquín Fargas' work is the concern regarding the continuation of humanity, the climate change and the consequences that it could bring and that could end with the extinction of human beings. In his project Immortality, the artist proposed the idea of an organism that can remain forever alive without being a victim of the deterioration of the body. Thus, he proposes a bioreactor in which a culture of cardiac cells (called immortal cells by the artist) is housed, which have the quality of beating and synchronizing with each other, and which receive the stimulus of the visitors to the work through multimedia systems that alter and accelerate the rhythm of the beat, linking the presence of other beings to the greater vitality of the cell culture. This combination of impulses makes it possible to generate the metaphor of a complex organic system that beats eternally and never ages.

Robotika, taking up the artist's concerns, is a trigger for society to ask itself about the future: Are we human beings in a position to guarantee the perpetuity of humans? Are we willing to delegate the future to an artificial intelligence? Will climate change end the possibilities for developing human life on the planet? Obviously this artwork does not seek to obtain scientific conclusions about the cryopreservation of embryos or planetary travel, it simply confronts us with the question of whether we are prepared as humans to face the challenges that the near future will bring, one of which is of course artificial intelligence.

Robotika seeks to show that perhaps humans must delegate its care to an artificial intelligence in order to achieve its preservation.

The work consists of an exoskeleton that contains and moves a faceless mannequin. The prototype is prepared to hold a baby at its breast. The robot also has a camera that looks towardsits arms and has an algorithm that allows it to detect when a baby's face appears in its lap. At that moment Robotika becomes active, illuminates the screen that covers her face and begins to cradle the child, singing and telling stories, offering emotional support. At the same time, she feeds the algorithm with the babies' reactions to improve the techniques and strategies of care.

One of the most significant questions regarding the conception of the work was whether to give the robot a human aspect. This was a controversial point in the development of the work, at first the artist thought of giving it a human shape, but then the idea was evolving towards a place where there was no competition or imitation of humans. It was focused precisely on the fact that the artificial intelligence intended to care and shelter human possibilities of future development in other places of the Universe wasn't human alike, thus strengthening its condition of artificial intelligence.

The work was presented in two modalities, a performatic one in which it shows how it works with a human baby and an exhibition one in which it interacts with toy babies.

The experience achieved by LabLat in training artificial intelligence algorithms from the development of this work has been increasing and surely soon will continue to advance on this path. Several projects based on these technologies are currently under development.

\section{Conclusion}

There is no doubt that artificial intelligence will become in a few years an essential element for the development of society. Even in Latin America, where social inequalities are more profound than in other continents, the way in which many tasks are carried out will surely be incorporated and modified.

Artists at the forefront of change make this reality visible to us today. The jobs of the future will be different, artificial intelligence will replace some of the positions that exist today. It will be necessary to train future generations to perform tasks that does not yet exist. This is an unavoidable challenge for education systems that must address these issues with the speed and rigor required.

Climate change and planetary travel, that today seems to be a distant reality, are the object of artistic proposals in order to help society to deeply reflect on these issues.

The new technologies propose to humanity new ethical challenges, about the maintenance of privacy and individuality among other conflicts, which will undoubtedly have to be taken up by the legislative systems at the same time as the copyright of artworks generated by algorithms in an autonomous way.

In this context, the Latin American Bio Art Laboratory represents a very interesting possibility for artists, scientists and technologists to apply their knowledge and their art in order to present society with artistic works that make this uncertain and near future visible.

Art has already begun to use artificial intelligence; this intelligence can generate new patterns but at the moment it is not possible to foresee that it can bring forth that creative spirit that distinguishes human beings.

\section{References}

[1] KLEe, P. (2008). Teoría del arte moderno (Buenos Aires City: EdicionesCaldén).

[2] MoMA's Marron Atrium, Opening Season 2019. Available at: https://www.moma.org/calendar/exhibitions/5080 
[3] DíAz, L. (15 Nov 2016). Del bioarte al espacio exterior: una obrapensada para gravedad cero. Available at: https://www.lanacion.com.ar/cultura/del-bioarte-alespacio-exterior-una-obra-pensada-para-gravedad-ceronid1956347.

[4] Christie's (12 Dec 2018). Is artificial intelligence set to become art's next medium? Available at: https://www.christies.com/features/A-collaborationbetween-two-artists-one-human-one-a-machine-9332$\underline{1 . \operatorname{aspx}}$

[5] Russell Stuart, Peter Norvig. N. (2014). Inteligencia Artificial. Un enfoque modern (Madrid: Pearson Educación).

[6] Moriello Sergio (2001). Inteligencias sintéticas. Alsina, Buenos Aires.

[7] Moriello Sergio (2005). Inteligencia natural y sintética. Nueva Librería, Buenos Aires.

[8] GARZÓN T. NÉSTOR M., TORRES S. LuIS C. (2011). Algoritmos genéticos. Universidad Autónoma de Colombia, Bogotá

[9] Garzón T. NÉStor M., Torres S. Luis C. (2012). Inteligencia artificial. Principios básicos. Editorial Académica Española, España.

[10] SeARle,J.(2000). El misterio de la conciencia. Madrid: Paidós.

[11] KAKU, M. (2014). El futuro de nuestra mente. Bogotá: Debate.

[12] Google Experiments Art \& Culture. Available at: https://artsexperiments.withgoogle.com/freefall/timeline\#3 1680.00,119.00,40.00,31680.00,119.00,0.00

[13] Processing. Available at: https://processing.org/

[14] DCGAN. Available at: https://github.com/robbiebarrat/artDCGAN

[15] LóPEZ De Mántaras BAdía, R. (2013). Computational Creativity. Arbor, 189 (764): a082. doi: http://dx.doi.org/10.3989/arbor.2013.764n6005 